\title{
Comparison of nutritional intake, body composition, bone mineral density, and isokinetic strength in collegiate female dancers
}

\author{
Se-Na Lim, Joo-Hee Chai, Jong-Kook Song, Myong-Won Seo, Hyun-Bae Kim* \\ Department of Physical Education, College of Physical Education, Kyung Hee University, Yongin, Korea
}

This study compared nutritional intake, body composition, bone mineral density, and isokinetic strength by dance type in collegiate female dancers. The study subjects included Korean dancers $(n=12)$, ballet dancers $(n=13)$, contemporary dancers $(n=8)$, and controls $(n=12)$. Nutritional intake was estimated using the Computer Aided Nutritional Analysis Program. Body composition and bone mineral density were measured using dual-energy X-ray absorptiometry. Isokinetic knee joint strength was measured by Cybex 770-NORM. All statistical analyses were performed by SAS 9.2. Means and standard deviations were calculated using descriptive statistics. One-way analysis of variance was applied to evaluate nutritional intake, body composition, bone mineral density, and isokinetic strength differences. Duncan multiple range test was used for post hoc testing. A level of significance was set at $P<0.05$. The study results indicated no significant differences in nutritional in- take among dancer types. Despite no significant differences in body composition among dancer types, contemporary and ballet dancers had lower body fat percentages than controls $(P<0.05)$. No significant differences were seen in bone mineral density and bone mineral contents among dancer types. No significant differences were found in isokinetic strength in right or left knee flexion and extension at $60 \% \mathrm{sec}$ $(P<0.05)$. There were significant differences in body composition and isokinetic strength between dancer groups and the control group. Further studies of different professional dance type and more scientific methods of dance training are needed.

Keywords: Korean dance, Ballet, Contemporary dance, Body composition, Bone mineral density, Isokinetic strength

\section{INTRODUCTION}

While dance has evolved as a pure art, it has reached the level where professional dancers require intense practice to master challenging techniques and provide high-quality performances, which require physical strength (Kushner et al., 1992). With this physical limitation, a variety of methods have been suggested to improve dance-related issues, and physiological and physical needs have been highlighted as combined with sports science (Gupta et al., 2004; Koutedakis and Jamurtas, 2004).

Most professional dancers experience insufficient nutrient intake considering the amount of practice in which they engage to ensure high-quality performances and maintain their body shape
(Jacobi et al., 2004; Thomas et al., 2005). In the case of Brazilian professional dancers, no statistically significant difference was seen, but both male $(29.5 \%)$ and female $(31.1 \%)$ dancers had abnormal dietary patterns (Ribeiro and da Veiga, 2010). Dancers' dissatisfaction about their body shapes reportedly affects their dietary attitude, resulting in nutritional imbalances, menstrual irregularities, body composition imbalances, and bone mineral density (BMD) decreases, and it can even negatively impact muscular function (de Bruin et al., 2009; Hincapié and Cassidy, 2010; Nattiv et al., 2007; Otis et al., 1997). In addition, professional dancers from the Bolshoi Ballet exhibited statistically significantly lower body mass index, body fat percentage, and body fat amount compared to students from the College of Physical Education.
${ }^{*}$ Corresponding author: Hyun-Bae Kim

Department of Physical Education, College of Physical Education, Kyung Hee University, 1732 Deogyeong-daero, Giheung-gu, Yongin 17104, Korea Tel: +82-31-201-2716, Fax: +82-31-204-8117, E-mail: hbkim5@khu.ac.kr Received: October 8, 2015 / Accepted: November 13, 2015
This is an Open Access article distributed under the terms of the Creative Commons Attribution Non-Commercial License (http://creativecommons.org/licenses/by-nc/3.0/) which permits unrestricted non-commercial use, distribution, and reproduction in any medium, provided the original work is properly cited. 
Lean tissue was also low in female dancers, demonstrating that intense practice altered body composition (Ferrari et al., 2013).

In terms of BMD, approximately $83 \%$ of ballet dancers observed by Ringham et al. (2006) experienced eating disorders, and the study reported that dancers who did not have a normal diet maintained a decreased BMD compared to the control group (Quintas et al., 2003). In particular, weight control measures, eating disorders, and dietary restrictions that began in adolescence tended to decrease BMD (Hincapié and Cassidy, 2010; Misra, 2008; Tanaka et al., 2007), and Foldes et al. (1997) showed that dancers who engaged in highly intense practice when young and aiming to become professional ballet dancers tended to have decreased BMD.

Furthermore, decreased BMD can expose dancers to increased risks of fall-induced bone fracture, resulting in musculoskeletal damage or sarcopenia, which can potentially limit a dancer's ability to perform expressive movements (Ducher et al., 2011; Hincapié and Cassidy, 2010). In particular, improved muscular strength in the lower limbs is essential to easing the technical challenges of body expression. Although its satisfaction can lead to efficient movement and enable a higher and farther jumping or leaping takeoff, which facilitates improvements to the dancer's art, muscular function reportedly varies by dance type (So et al., 1994). Taken together, a dancer's inappropriate diet can negatively impact their body composition, BMD, and lower-limb muscular function (Hincapié and Cassidy, 2010).

As mentioned above, although previous studies suggested various implications about the study of dance, an investigation of nutritional intake and analysis of the individually required factors such as body composition, BMD, and isokinetic muscular function are required to further understand the physiological features of dance. Therefore, this study aimed to understand differences in these factors by dance type by investigating the nutritional intake, body composition, BMD, and isokinetic muscular function of students majoring in contemporary dance, ballet, and Korean dance. Furthermore, by comparing the physical features of students who were not dance majors with those who were dance majors, we obtained health-related information in an effort to provide approaches to solving dance performance problems and improve function.

\section{MATERIALS AND METHODS}

\section{Study subjects}

The study subjects included 12 students majoring in Korean dance, 13 students majoring in ballet, eight students majoring in
Table 1. Subject characteristics by study group

\begin{tabular}{lcccc}
\hline & \multicolumn{4}{c}{ Female dance group } \\
\cline { 2 - 5 } Characteristic & $\begin{array}{c}\text { Korean } \\
(\mathrm{n}=12)\end{array}$ & $\begin{array}{c}\text { Ballet } \\
(\mathrm{n}=13)\end{array}$ & $\begin{array}{c}\text { Contemporary } \\
(\mathrm{n}=8)\end{array}$ & $\begin{array}{c}\text { Control } \\
(\mathrm{n}=12)\end{array}$ \\
\hline Body weight $(\mathrm{kg})$ & $54.5 \pm 6.45$ & $51.0 \pm 4.70$ & $54.7 \pm 6.89$ & $53.0 \pm 6.38$ \\
Standing height $(\mathrm{cm})$ & $164.9 \pm 3.29$ & $163.3 \pm 3.55$ & $164.8 \pm 3.42$ & $160.3 \pm 5.10$ \\
\hline
\end{tabular}

Values are presented as mean \pm standard deviation.

contemporary dance, and 12 nondance majors at Kyung Hee University located in Seoul through simple random sampling. Thus, a total of 45 students (age range, 18-20 yr) participated in this study after they volunteered to participate and signed an informed consent form. None of the participants had any physical defects or diseases and were not on any medication. The participants' characteristics are shown in Table 1.

\section{Nutritional intake}

Nutritional intake was self-recorded over $24 \mathrm{hr}$ on a dietary record. Nutritional intake was recorded for a total of three days, including two weekdays and one weekend day. The survey employed the Computer Aided Nutrition Analysis Program generated by The Korean Nutrition Society and aimed to investigate the intakes of total calories, the three major nutrients, calcium, phosphorus, iron, and zinc.

\section{Body composition}

Body composition was measured using dual X-ray absorptiometry (DXA; QDR-4500W; Hologic, Marlborough, MA, USA) to investigate lean tissue and body fat percentage.

\section{Bone mineral density}

BMD was measured with DXA assessing whole body BMD and it was recorded in $\mathrm{g} / \mathrm{cm}^{2}$.

\section{Isokinetic muscular function measurement}

Isokinetic dynamometry (Cybex 770-NORM, Cybex International, Medway, MA, USA) was performed to evaluate flexion and extension of the right and left knees. Each test included three maximal contractions at $60 \%$ sec for muscle strength. Each isokinetic contraction was performed through a full range of motion, and data were normalized to each participant's body weight and calculated as torque $(\mathrm{N} \cdot \mathrm{m} / \mathrm{kg}) \times 100$.

\section{Data process method}

Statistical analyses were performed by using SAS ver. 9.2 (SAS 
Institute Inc., Cary, NC, USA), and mean and standard deviation for each variable were computed using descriptive statistics. Oneway analysis of variance was performed to test the statistical significance of body build, nutritional intake, body composition, BMD, and isokinetic muscular function of the four groups according to sport type. Post boc testing was performed using Duncan multiple range test. For all statistical tests, a $P<0.05$ was considered as statistically significant.

\section{RESULTS}

This study compared and analyzed nutritional intake, body composition, BMD, and isokinetic muscular function in collegiate female Korean dance majors ( $\mathrm{n}=12)$, ballet majors $(\mathrm{n}=13)$, modern dance majors ( $n=8)$, and controls $(n=12)$. The results are described below.

\section{Comparison of nutritional intake}

The nutritional intake analysis results for each group are listed in Table 2. There was no statistically significant difference in mean total calories, protein, fat, carbohydrate, calcium, phosphorus, or iron intake among the different groups of dance majors. There was also no statistically significant difference between the dance students and controls.

\section{Comparison of body composition}

The body composition analysis results in each group are summarized in Table 3. No statistically significant difference in mean lean tissue was observed among the dance student groups or between the dance students and controls. However, mean percentage body fat was significantly different between the groups $(F=5.20$, $P<0.004)$. Based on post hoc test results, the Korean dance group did not exhibit a statistically significant difference from the other three groups $(27.7 \% \pm 4.64 \%)$, whereas the ballet $(24.8 \% \pm 3.12 \%)$

Table 2. Comparisons of nutritional intake condition parameters by dance types in collegiate female dancers

\begin{tabular}{|c|c|c|c|c|c|c|}
\hline \multirow{2}{*}{ Variable } & \multicolumn{4}{|c|}{ Female dance group } & \multirow{2}{*}{$F$} & \multirow{2}{*}{$P>F$} \\
\hline & Korean $(n=12)$ & Ballet $(n=13)$ & Contemporary $(\mathrm{n}=8)$ & Control $(n=12)$ & & \\
\hline Total calories (kcal) & $1,100.9 \pm 472.89$ & $1,214.4 \pm 390.32$ & $1,454.1 \pm 478.59$ & $1,306.9 \pm 332.53$ & 1.26 & 0.30 \\
\hline Protein (g) & $43.3 \pm 17.92$ & $45.4 \pm 15.31$ & $55.3 \pm 18.95$ & $50.9 \pm 15.37$ & 1.06 & 0.38 \\
\hline Fat (g) & $35.8 \pm 17.55$ & $36.0 \pm 10.87$ & $49.8 \pm 17.82$ & $40.4 \pm 11.57$ & 1.90 & 0.14 \\
\hline Carbohydrate (g) & $151.9 \pm 63.50$ & $177.8 \pm 63.70$ & $196.3 \pm 67.99$ & $176.7 \pm 46.17$ & 0.93 & 0.44 \\
\hline Ca (mg) & $269.2 \pm 150.14$ & $364.6 \pm 108.67$ & $367.4 \pm 144.18$ & $350.2 \pm 124.85$ & 1.44 & 0.25 \\
\hline$P(m g)$ & $557.5 \pm 257.41$ & $629.4 \pm 215.38$ & $736.9 \pm 271.83$ & $677.1 \pm 206.70$ & 1.05 & 0.38 \\
\hline $\mathrm{Fe}(\mathrm{mg})$ & $7.2 \pm 3.53$ & $8.1 \pm 3.23$ & $8.9 \pm 2.74$ & $9.7 \pm 5.28$ & 0.87 & 0.47 \\
\hline $\mathrm{Zn}(\mathrm{mg})$ & $5.1 \pm 2.29$ & $5.6 \pm 2.08$ & $6.5 \pm 2.40$ & $6.1 \pm 2.20$ & 0.81 & 0.50 \\
\hline
\end{tabular}

Values are presented as mean \pm standard deviation.

Table 3. Comparisons of body composition parameters by dance type in collegiate female dancers

\begin{tabular}{lcccccc}
\hline \multirow{2}{*}{ Parameter } & \multicolumn{2}{c}{ Female dance group } & $F$ & \\
\cline { 2 - 4 } & Korean $(\mathrm{n}=12)$ & Ballet $(\mathrm{n}=13)$ & Contemporary $(\mathrm{n}=8)$ & Control $(\mathrm{n}=12)$ & & \\
\hline Lean tissue $(\mathrm{kg})$ & $36.8 \pm 3.00$ & $36.5 \pm 2.85$ & $39.3 \pm 2.10$ & $35.4 \pm 4.63$ & 2.07 & 0.12 \\
Percent body fat $(\%)$ & $27.7 \pm 4.64^{\mathrm{a}, \mathrm{b})}$ & $24.8 \pm 3.12^{\mathrm{b})}$ & $24.5 \pm 4.57$ & $30.0 \pm 3.09$ & 5.2 & $0.004^{*}$ \\
\hline
\end{tabular}

Values are presented as mean \pm standard deviation.

a),b) Same alphabet indicates no significant difference among groups. ${ }^{*} P<0.05$.

Table 4. Comparisons of total body BMD by dance type in collegiate female dancers

\begin{tabular}{|c|c|c|c|c|c|c|}
\hline & & Femal & nce group & & E & $D, E$ \\
\hline & Korean $(n=12)$ & Ballet $(n=13)$ & Contemporary $(\mathrm{n}=8)$ & Control $(n=12)$ & 1 & 11 \\
\hline Total BMD $\left(\mathrm{g} / \mathrm{cm}^{2}\right)$ & $1.1 \pm 0.06$ & $1.1 \pm 0.06$ & $1.1 \pm 0.06$ & $1.1 \pm 0.09$ & 1.6 & 0.2 \\
\hline
\end{tabular}

Values are presented as mean \pm standard deviation.

$\mathrm{BMD}$, bone mineral density. 
Table 5. Comparisons of isokinetic muscular strength at $\% \mathrm{BW} 60^{\circ} / \mathrm{sec}$ by dance type in collegiate female dancers

\begin{tabular}{|c|c|c|c|c|c|c|}
\hline \multirow{2}{*}{ Isokinetic muscular strength } & \multicolumn{4}{|c|}{ Female dance group } & \multirow{2}{*}{$F$} & \multirow{2}{*}{$P>F$} \\
\hline & Korean $(n=12)$ & Ballet $(n=13)$ & Contemporary $(n=8)$ & Control $(n=12)$ & & \\
\hline \multicolumn{7}{|c|}{ Extensor peak torque \%BW $(\mathrm{N} \cdot \mathrm{m} / \mathrm{kg})$} \\
\hline Right & $178.5 \pm 19.48$ & $176.0 \pm 34.68$ & $184.3 \pm 19.16$ & $160.5 \pm 28.11$ & 1.52 & 0.22 \\
\hline Left & $176.0 \pm 23.38$ & $170.6 \pm 37.79$ & $180.5 \pm 18.49$ & $151.5 \pm 37.42$ & 1.79 & 0.17 \\
\hline \multicolumn{7}{|c|}{ Flexor peak torque \%BW $(\mathrm{N} \cdot \mathrm{m} / \mathrm{kg})$} \\
\hline Right & $112.0 \pm 17.03$ & $114.0 \pm 20.72$ & $114.3 \pm 26.42$ & $100.8 \pm 18.41$ & 1.14 & 0.35 \\
\hline Left & $110.1 \pm 18.93$ & $113.8 \pm 26.57$ & $112.6 \pm 18.87$ & $94.4 \pm 23.37$ & 1.87 & 0.15 \\
\hline
\end{tabular}

Values are presented as mean \pm standard deviation.

$\% \mathrm{BW}, \%$ body weight.

and contemporary dance $(24.5 \% \pm 4.57 \%)$ groups had a statistically significantly lower mean body fat content than the control group $(30.0 \% \pm 3.09 \%)$. On the other hand, there was no statistically significant difference between the Korean dance, ballet, and contemporary dance groups.

\section{Comparison of BMD}

The results comparing whole body BMD among groups are shown in Table 4. No statistically significant difference was observed in mean whole body BMD among the different dance type groups or even between dance majors and nondance majors in the control group.

\section{Comparison of isokinetic muscular function}

The comparison result of isokinetic muscular function by group is shown in Table 5.

\section{Isokinetic extensor $60 \% \mathrm{sec}$ and Isokinetic flexor $60 \% \mathrm{sec}$}

No statistically significant difference was detected on the right or left side of the mean isokinetic extensor at $60^{\circ} / \mathrm{sec}$ among the dance groups or between any dance group and the control group. No statistically significant difference was detected on the right or left side of the mean isokinetic flexor at $60 \%$ sec among the dance groups or between any dance group and the control group.

\section{DISCUSSION}

\section{Nutritional intake}

Although it is necessary for dancers to obtain sufficient nutrition to ensure their best performance, dancers experience limited nutritional intake to maintain their body image and shape because dance is an art expressed through body motions. Thus, dancers are at risk of minimal nutritional intake, which can lead to deficiencies of micronutrients such as iron, calcium, and vitamin D (Sousa et al., 2013).

No difference was observed in any of the nutritional intake values among participants in this study. However, while the Korean National Health and Nutrition Examination Survey (KNHANES V-3) (Ministry of Health \& Welfare, Korea Centers for Disease Control and Prevention, 2013) revealed a total energy intake of $1,779 \mathrm{kcal}$ from similar age groups, the mean caloric intakes were $1,454.1 \pm 478.59 \mathrm{kcal}$ in the contemporary dance group, $1,213.4 \pm 390.32 \mathrm{kcal}$ in the ballet group, and 1,100.9 472.89 $\mathrm{kcal}$ in the Korean dance group in the present study, while that in the control group was $1,306.9 \pm 332.53 \mathrm{kcal}$. These results indicated that total nutritional intake expenditure is insufficient for female nondance majors and dance majors, highlighting the need for an increased nutritional intake for all groups surveyed in this study. In this regard, Lagowska et al. (2014) provided nutritional treatment to ballet dancers for 9 months. The study results showed that the treatment improved nutritional intake from $1,640 \pm 412$ to $2,368 \pm 182 \mathrm{kcal}$, while fat mass showed no statistical significant increase. Total energy expenditure increased significantly $(P<0.05)$, whereas fat mass did not. Based on their results, nondance and dance majors should avoid limiting their intake because of body image concerns. Furthermore, to decrease nutritional imbalances and related diseases, dancers require a minimum of $30 \mathrm{kcal}$ of fat free mass as per $\mathrm{kg}$ of body weight daily as well as the necessary energy expended during training. In terms of macronutrients, the daily recommendation per $\mathrm{kg}$ of body weight is $3-5 \mathrm{~g}$ for carbohydrate, 1.2-1.7 $\mathrm{g}$ for protein, and $20 \%-35 \%$ for fat (Sousa et al., 2013). This study showed that mean carbohydrate intake was $151.9 \pm 63.5 \mathrm{~g}$ for the Korean dance group followed by $176.7 \pm 46.17 \mathrm{~g}$ for the control group, $177.8 \pm 63.7 \mathrm{~g}$ for ballet group, and $196.3 \pm 67.99 \mathrm{~g}$ for the contemporary dance group, which was converted to $2.8,3.3,3.4$, and $3.5 \mathrm{~g}$ of intake level per $\mathrm{kg}$ of body weight, respectively, showing Korean dance group slightly did not meet the daily recommenda- 
tion. In addition, mean protein intake was $43.3 \pm 17.92 \mathrm{~g}$ for the Korean dance group, $45.4 \pm 15.31 \mathrm{~g}$ for ballet group, $50.9 \pm 15.37$ $\mathrm{g}$ for the control group, and $55.3 \pm 18.95 \mathrm{~g}$ for the contemporary dance group, which was equivalent to intake per body weight of $0.8,0.9,1.0$, and $1.0 \mathrm{~g}$ for individual groups when converted to daily recommendation per body weight, suggesting that all four groups experienced remarkably insufficient protein intake.

Lagowska et al. (2014) reported that the nutritional intake of ballet dancers was $342.0 \pm 33.2,85.3 \pm 9.3$, and $73.2 \pm 15.9 \mathrm{~g}$ for carbohydrate, protein, and fat, respectively, values that are much higher than those of the students surveyed in this study. Thus, as shown in Łagowska et al. (2014), it is essential to have treatment or approaches to elevate macronutrient intake level up to the daily recommended intake. It is also important to change perception of dancers about dietary intake for their health and future and to build a system that allows continuous management through nutritional intake monitoring.

\section{Body composition}

Systemic and proper body composition and its maintenance are essential for dancers to perform challenging and high-quality repetitive movements (Rafferty, 2010). However, most dancers pay more attention to their body shapes than body compositions. In this regard, the mean body fat contents of the participants of the present study were $30 \% \pm 3.09 \%$ for the control group, $27.7 \% \pm 4.64 \%$ for the Korean dance group, $24.8 \% \pm 3.12 \%$ for the ballet group, and $24.5 \% \pm 4.57 \%$ for the contemporary dance group, and the values of the contemporary dance and ballet groups were significantly different from that of the control group $(P<0.05)$. Friesen et al. $(2011)$ revealed $25.9 \% \pm 4.2 \%$ and $32.0 \% \pm 5.9 \%$ as the body fat contents of contemporary dancers and nondancers, respectively, while Yang et al. (2010) showed that adolescent dancers and nondancers had body fat contents of $25 \% \pm 0.05 \%$ and $34 \% \pm 0.04 \%$, respectively. These studies showed a similar tendency to the results of the present study for the contemporary dance and ballet groups but not the Korean dance group.

However, in the case of lean tissue, no statistically significant difference was observed compared to the control group, showing $39,329.7 \pm 2,997.67 \mathrm{~g} / \mathrm{cm}^{2}$ for the contemporary dance group, $36,772.4 \pm 3,004.82 \mathrm{~g} / \mathrm{cm}^{2}$ for the Korean dance group, 36,503.1 \pm $2,849.29 \mathrm{~g} / \mathrm{cm}^{2}$ for the ballet group, and $35,421 \pm 4,631.5 \mathrm{~g} / \mathrm{cm}^{2}$ for the control group. This result suggests that nondance and dance majors have similar levels of lean tissue. Therefore, it is necessary for dancers to increase their lean tissue to better their perfor- mance, for which weight training or weight-bearing exercise programs are highly recommended. When this training is pursued, dancers' capacities to execute challenging movements that require artistic components and professional dancing techniques are expected to improve.

\section{Bone mineral density}

Eating disorders, menstruation disorders, and low BMD, either alone or in combination, are risk factors for female dancers (Hincapié and Cassidy, 2010). Some studies related to BMD reported that dancers had decreased BMD (Hoch et al., 2011), leading to the risk of osteoporosis, whereas other studies reported opposite results that the weight-bearing movements improved dancers' BMD (Amorim et al., 2015). This study did not show any difference in BMD among participants; in fact, all four groups maintained a normal BMD range level $\left(1.1 \pm 0.06-0.09 \mathrm{~g} / \mathrm{cm}^{2}\right)$ despite a low nutritional intake. These results were consistent with those of Yang et al. (2010) in which Chinese adolescent dancers showed a relatively higher BMD despite a low nutritional intake and menstrual disorder. The study mentioned that the results could be due to their high levels of weight-bearing physical activity.

In this study, we also observed a normal BMD range despite a continuous diet restriction and low nutritional intake, which is thought to be because dancing movements such as kicking, leaping, hopping, turning, jumping, and twisting apply intense mechanical stress to the bones through weight-bearing.

However, Friesen et al. (2011) showed a left hip BMD of $1.2 \pm 0.11 \mathrm{~g} / \mathrm{cm}^{2}$ and $1.1 \pm 0.10 \mathrm{~g} / \mathrm{cm}^{2}$ for collegiate contemporary dancers and nondancers, respectively, indicating a statistically significant difference between the groups $(P<0.05)$, a finding that was inconsistent with those of this study. However, BMD could vary among body parts and dance types and levels. Thus, the measurement of BMD in different body parts as well as the whole body is recommended to obtain more accurate data.

\section{Isokinetic strength}

The evaluation of muscular function using isokinetic measurement equipment can be a useful indicator to assess the efficacy of sports injury prevention and recovery and is a reliable measurement method for muscular strength and endurance (Cools and Geerooms, 2007). From the analysis of isokinetic strength, no statistically significant difference was observed between the extensor and flexor at $60 \%$ sec for the left or right sides. This result means that female nondance and dance majors have similar muscular strength, which might limit the ability of the latter to perform 
active and accurate movements such as standing, locomotion, or dynamic jumping or turning. Thus, it was reported that plyometric training would be proper for dance major students to efficiently improve quadriceps femoris strength, which is critical to dance performance (Sáez-Sáez de Villarreal et al., 2010; Trzaskoma et al., 2010). It is also important that they maintain balanced muscle strength of the biceps femoris, which plays an important role as a flexor in the lower limbs, and resistance exercises such as leg curls are required to improve flexor strength. In addition, if professional approaches such as weight training can be used to overcome difficulties executing active movements and technical challenges, the oxidative function of slow muscle fibers will develop and improve mitochondrial function within the cells, leading to a potential increase in muscular function (Johnston et al, 2008) and more efficient execution of dance performance.

\section{CONFLICT OF INTEREST}

No potential conflict of interest relevant to this article was reported.

\section{REFERENCES}

Amorim T, Wyon M, Maia J, Machado JC, Marques F, Metsios GS, Flouris AD, Koutedakis Y. Prevalence of low bone mineral density in female dancers. Sports Med 2015;45:257-268.

Cools AM, Geerooms E, Van den Berghe DF, Cambier DC, Witvrouw EE. Isokinetic scapular muscle performance in young elite gymnasts. J Athl Train 2007;42:458-463.

de Bruin AP, Bakker FC, Oudejans RR. Achievement goal theory and disordered eating: relationships of disordered eating with goal orientations and motivational climate in female gymnasts and dancers. Psychol Sport Exerc 2009;10:72-79

Ducher G, Kukuljan S, Hill B, Garnham AP, Nowson CA, Kimlin MG, Cook J. Vitamin D status and musculoskeletal health in adolescent male ballet dancers a pilot study. J Dance Med Sci 2011;15:99-107.

Ferrari EP, Silva DA, Martins CR, Fidelix YL, Petroski EL. Morphological characteristics of professional ballet dancers of the Bolshoi theater company. Coll Antropol 2013;37 Suppl 2:37-43.

Foldes AJ, Danziger A, Constantini N, Popovtzer MM. Reduced ultrasound velocity in tibial bone of young ballet dancers. Int J Sports Med 1997;18:296-299.

Friesen KJ, Rozenek R, Clippinger K, Gunter K, Russo AC, Sklar SE. Bone mineral density and body composition of collegiate modern dancers. J Dance Med Sci 2011;15:31-36.
Gupta A, Fernihough B, Bailey G, Bombeck P, Clarke A, Hopper D. An evaluation of differences in hip external rotation strength and range of motion between female dancers and non-dancers. Br J Sports Med 2004;38:778-783.

Hincapié CA, Cassidy JD. Disordered eating, menstrual disturbances, and low bone mineral density in dancers: a systematic review. Arch Phys Med Rehabil 2010;91:1777-1789.e1.

Hoch AZ, Papanek P, Szabo A, Widlansky ME, Schimke JE, Gutterman DD. Association between the female athlete triad and endothelial dysfunction in dancers. Clin J Sport Med 2011;21:119-125.

Jacobi C, Hayward C, de Zwaan M, Kraemer HC, Agras WS. Coming to terms with risk factors for eating disorders: application of risk terminology and suggestions for a general taxonomy. Psychol Bull 2004; 130:19-65.

Johnston AP, De Lisio M, Parise G. Resistance training, sarcopenia, and the mitochondrial theory of aging. Appl Physiol Nutr Metab 2008;33: 191-199.

Koutedakis Y, Jamurtas A. The dancer as a performing athlete: physiological considerations. Sports Med 2004;34:651-661.

Kushner S, Reid DK, Saboe L, Penrose T. Isokinetic torque values of the hip in professional Ballet dancers. Clin J Sport Med 1992;2:114-120.

Lagowska K, Kapczuk K, Jeszka J. Nine-month nutritional intervention improves restoration of menses in young female athletes and ballet dancers. J Int Soc Sports Nutr 2014;11:52.

Ministry of Health \& Welfare, Korea Centers for Disease Control and Prevention. Korea Health Statistics 2012: Korea National Health and Nutrition Examination Survey (KNHANES V-3). Cheongwon: Ministry of Health \& Welfare, Korea Centers for Disease Control and Prevention; 2013.

Misra M. Bone density in the adolescent athlete. Rev Endocr Metab Disord 2008;9:139-144.

Nattiv A, Loucks AB, Manore MM, Sanborn CF, Sundgot-Borgen J, Warren MP; American College of Sports Medicine. American College of Sports Medicine position stand. The female athlete triad. Med Sci Sports Exerc 2007;39:1867-1882.

Otis CL, Drinkwater B, Johnson M, Loucks A, Wilmore J. American College of Sports Medicine position stand. The Female Athlete Triad. Med Sci Sports Exerc 1997;29:i-ix.

Quintas ME, Ortega RM, López-Sobaler AM, Garrido G, Requejo AM. Influence of dietetic and anthropometric factors and of the type of sport practised on bone density in different groups of women. Eur J Clin Nutr 2003;57 Suppl 1:S58-62.

Rafferty S. Considerations for integrating fitness into dance training. J Dance Med Sci 2010;14:45-49.

Ribeiro LG, da Veiga GV. Risk behaviors for eating disorders in Brazilian 
dancers. Int J Sports Med 2010;31:283-288.

Ringham R, Klump K, Kaye W, Stone D, Libman S, Stowe S, Marcus M. Eating disorder symptomatology among ballet dancers. Int J Eat Disord 2006;39:503-508.

Sáez-Sáez de Villarreal E, Requena B, Newton RU. Does plyometric training improve strength performance? A meta-analysis. J Sci Med Sport 2010;13:513-522.

So $\mathrm{CH}$, Siu TO, Chan KM, Chin MK, Li CT. Isokinetic profile of dorsiflexors and plantar flexors of the ankle: a comparative study of élite versus untrained subjects. Br J Sports Med 1994;28:25-30.

Sousa M, Carvalho P, Moreira P, Teixeira VH. Nutrition and nutritional issues for dancers. Med Probl Perform Art 2013;28:119-123.

Tanaka K, Hisada K, Unno K, Iijima M, Unno A, Tokita A, Shimizu T, Ya- mashiro Y. Bone mineral density in children and adolescent girls with anorexia nervosa in Japan. Pediatr Int 2007;49:637-640.

Thomas JJ, Keel PK, Heatherton TF. Disordered eating attitudes and behaviors in ballet students: examination of environmental and individual risk factors. Int J Eat Disord 2005;38:263-268.

Trzaskoma L, Tihanyi J, Trzaskoma Z. The effect of a short-term combined conditioning training for the development of leg strength and power. J Strength Cond Res 2010;24:2498-2505.

Yang LC, Lan Y, Hu J, Yang YH, Zhang Q, Huang ZW, Piao JH. Relatively high bone mineral density in Chinese adolescent dancers despite lower energy intake and menstrual disorder. Biomed Environ Sci 2010;23:130136. 